\title{
EDITORIAL
}

\section{The Cytoscape Automation app article collection [version 1;}

\section{peer review: not peer reviewed]}

\author{
Barry Demchak (D1, David Otasek1, Alexander R Pico(D2, Gary D Bader(D), \\ Keiichiro Ono1, Brett Settle1, Eric Sage1, John H Morris (iD) 4, William Longabaugh5, \\ Christian Lopes ${ }^{3}$, Michael Kucera ${ }^{3}$, Adam Treister (D)2, Benno Schwikowski6, \\ Piet Molenaar7, Trey Ideker ${ }^{1}$ \\ ${ }^{1}$ Department of Medicine, University of California, San Diego, La Jolla, CA, 92093, USA \\ ${ }^{2}$ Gladstone Institutes, San Francisco, CA, 95158, USA \\ ${ }^{3}$ The Donnelly Centre, University of Toronto, Toronto, ON, M5S 3E1, Canada \\ ${ }^{4}$ University of California, San Francisco, San Francisco, CA, 94143, USA \\ ${ }^{5}$ Institute for Systems Biology, Seattle, WA, 98109, USA \\ ${ }^{6}$ Inistitut Pasteur, Paris, 75015, France \\ ${ }^{7}$ Amsterdam Medical Centre, Ansterdam, 1105 AZ, The Netherlands
}

V1 First published: 20 Jun 2018, 7:800

https://doi.org/10.12688/f1000research.15355.1

Latest published: 20 Jun 2018, 7:800

https://doi.org/10.12688/f1000research.15355.1

\section{Abstract}

Cytoscape is the premiere platform for interactive analysis, integration and visualization of network data. While Cytoscape itself delivers much basic functionality, it relies on community-written apps to deliver specialized functions and analyses. To date, Cytoscape's CYREST feature has allowed researchers to write workflows that call basic Cytoscape functions, but provides no access to its high value app-based functions. With Cytoscape Automation, workflows can now call apps that have been upgraded to expose their functionality. This article collection is a resource to assist readers in quickly and economically leveraging such apps in reproducible workflows that scale independently to large data sets and production runs.

\section{Keywords}

Cytoscape, Automation, App, Network Biology, Network Analysis, Network Visualization

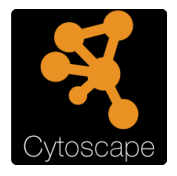

This article is included in the Cytoscape

gateway.

\section{Not Peer Reviewed \\ This article is an Editorial and has not been subject to external peer review.}

Any comments on the article can be found at the end of the article. 
Corresponding author: Barry Demchak (idekerlab.bdemchak@gmail.com)

Author roles: Demchak B: Conceptualization, Project Administration, Supervision, Writing - Original Draft Preparation; Otasek D: Software; Pico AR: Conceptualization, Software, Supervision, Writing - Review \& Editing; Bader GD: Funding Acquisition, Supervision; Ono K: Software; Settle B: Software; Sage E: Software; Morris JH: Software; Longabaugh W: Software, Writing - Review \& Editing; Lopes C: Software; Kucera M: Software; Treister A: Software; Schwikowski B: Funding Acquisition, Software; Molenaar P: Software; Ideker T: Funding Acquisition, Supervision

Competing interests: No competing interests were disclosed.

Grant information: This work was supported with funding from the National Resource for Network Biology (NRNB) under award number P41 GM103504 and the National Institute of General Medical Sciences (NIGMS) under award number R01 GM070743, both assigned to TI.

The funders had no role in study design, data collection and analysis, decision to publish, or preparation of the manuscript.

Copyright: ( 2018 Demchak B et al. This is an open access article distributed under the terms of the Creative Commons Attribution License, which permits unrestricted use, distribution, and reproduction in any medium, provided the original work is properly cited.

How to cite this article: Demchak B, Otasek D, Pico AR et al. The Cytoscape Automation app article collection [version 1; peer review: not peer reviewed] F1000Research 2018, 7:800 https://doi.org/10.12688/f1000research.15355.1

First published: 20 Jun 2018, 7:800 https://doi.org/10.12688/f1000research.15355.1 


\section{Editorial}

Cytoscape is an open source software platform for interactive analysis, integration and visualization of networks and network data ${ }^{1}$. At heart, Cytoscape provides basic network analysis functionality (e.g., network import/export, network data analysis, visualization and layout) in a menu-driven desktop format. Most importantly, it also enables and encourages users to add extensions (called apps) that deliver custom features important for specific workflows (e.g., ClueGO ${ }^{2}$ for enrichment analysis relative to various ontologies). To date, Cytoscape users can choose among over 330 apps written by over 550 authors.

In 2014, the CyREST app ${ }^{3}$ was created to allow external programs to exercise core Cytoscape functionality as part of custom workflows. By authoring such workflows in common languages (such as $\mathrm{R}$ and Python), users can combine the best features of Cytoscape with those available in languagespecific libraries, thus creating new value much more quickly and cheaply than writing conventional Cytoscape apps. Furthermore, such workflows can more easily integrate external applications (e.g., GenePattern and iGraph) and multiple large datasets. Finally, external workflows enable reproducibility not available using Cytoscape's standard mouse/keyboard/ display interaction mode.

In 2018, Cytoscape Automation was created to enable external workflows to also call functionality in apps. For an app to be callable, it must be upgraded to support automation via either a
Commands or Functions interface. As of March, 2018, app authors upgraded and released 22 apps.

This collection of Cytoscape app articles at F1000Research is intended to serve as a resource to researchers (as workflow authors) and app developers to understand the features and interfaces exposed by automation-enabled apps. They are written by the app authors themselves according to a template that calls for explaining newly available functions, how they can be called, and with real world examples. We intend that readers be able to quickly and economically incorporate Cytoscape app functionality as reproducible workflows that scale independently to large data sets and production runs.

\section{Data availability}

No data are associated with this article.

\section{Competing interests}

No competing interests were disclosed.

\section{Grant information}

This work was supported with funding from the National Resource for Network Biology (NRNB) under award number P41 GM103504 and the National Institute of General Medical Sciences (NIGMS) under award number R01 GM070743, both assigned to TI.

The funders had no role in study design, data collection and analysis, decision to publish, or preparation of the manuscript.
1. Pico AR Bader GD, Demchak B, et al: The Cytoscape app article collection [version 1; referees: not peer reviewed]. F1000Res. 2014; 3: 138. PubMed Abstract | Publisher Full Text | Free Full Text

2. Bindea G, Mlecnik B, Hackl H, et al:: ClueGO: a Cytoscape plug-in to decipher functionally grouped gene ontology and pathway annotation networks.
Bioinformatics. 2009: 25(8): 1091-1093.

PubMed Abstract | Publisher Full Text | Free Full Text

3. Ono K, Muetze T, Kolishovski G, et al:: CyREST: Turbocharging Cytoscape Access for External Tools via a RESTful API [version 1; referees: 2 approved]. F1000Res. 2015; 4: 478.

PubMed Abstract | Publisher Full Text | Free Full Text 
The benefits of publishing with F1000Research:

- Your article is published within days, with no editorial bias

- You can publish traditional articles, null/negative results, case reports, data notes and more

- The peer review process is transparent and collaborative

- Your article is indexed in PubMed after passing peer review

- Dedicated customer support at every stage

For pre-submission enquiries, contact research@f1000.com 